\title{
Publisher Correction: Collective behaviour can stabilize ecosystems
}

Benjamin D. Dalziel (1), Mark Novak (D), James R. Watson and Stephen P. Ellner (1)

Correction to: Nature Ecology \& Evolution https://doi.org/10.1038/s41559-021-01517-w, published online 12 August 2021.

In the version of this article initially published, there was an error in the caption wording for Fig. $2 c$,d. The text now reading "c Cycles in the number of consumer groups over time. d, Concordant cycles in resource abundance" has replaced the earlier caption text "c, The relationship between resource abundance and the number of ocnsumer groups. $\mathbf{d}$, Concordant cycles in resource abundance and the number of consumer groups." The changes have been made in the HTML and PDF versions of the article.

Published online: 15 December 2021

https://doi.org/10.1038/s41559-021-01645-3

() The Author(s), under exclusive licence to Springer Nature Limited 2021 